\title{
Tsafon
}

Revue d'études juives du Nord

77 | 2019

Contribution à l'histoire des traductions juives de la Bible hébraïque

\section{Les appropriations du discours antisémite. Comportements mimétiques et détournements carnavalesques}

\section{Françoise Marti}

\section{(2) OpenEdition \\ Journals}

Édition électronique

URL : https://journals.openedition.org/tsafon/2078

DOI : $10.4000 /$ tsafon. 2078

ISSN : 2609-6420

Éditeur

Association Jean-Marie Delmaire

Édition imprimée

Date de publication : 1 septembre 2019

Pagination : 168-170

ISSN : 1149-6630

Référence électronique

Françoise Marti, «Les appropriations du discours antisémite. Comportements mimétiques et détournements carnavalesques », Tsafon [En ligne], 77 | 2019, mis en ligne le 09 septembre 2019, consulté le 24 juin 2021. URL : http://journals.openedition.org/tsafon/2078 ; DOI : https://doi.org/ $10.4000 /$ tsafon. 2078

Ce document a été généré automatiquement le 24 juin 2021.

Tsafon. Revues d'études juives du Nord 


\title{
Les appropriations du discours antisémite. Comportements mimétiques et détournements carnavalesques
}

\author{
Françoise Marti
}

\section{RÉFÉRENCE}

Lormont, éditions Le Bord de l'eau,220 p., $24 €$.

1 La littérature française possède ses écrivains antisémites bien connus. Ce qui est moins connu, c'est la façon dont les écrivains juifs ont pu reprendre leurs stéréotypes, se risquant à l'ambiguïté. C'est à explorer cette littérature particulière que s'attellent les contributeurs du présent ouvrage.

2 Maxime Decout, faisant un large tour d'horizon littéraire, tente d'y débusquer la haine de soi ou un rapport problématique à l'identité juive. Distinguant renversement positif du stéréotype (chez Cohen ou Gary par exemple) et ambivalence du réemploi (chez Proust ou Nemirovsky), il souligne que le problème ne se pose plus de la même manière après la Deuxième Guerre mondiale.

3 L'ambiguïté de Heine, étudiée par Andrée Lerousseau, passe par la satire et le burlesque, avec des personnages cherchant en vain à s'assimiler en singeant les gentils, sans parvenir à masquer les traits distinctifs du Juif, sans renoncer au Witz (esprit humoristique). Adhésion ou autodérision? Amour ou haine? Cela reste indécidable. De la même façon, l'ambivalence de Proust (analysée par Béatrice Athias) s'exprime à travers des personnages juifs très différents : Swann, symbole de réussite remarquable, osant s'affirmer farouchement dreyfusard, et son double négatif, Bloch, tentant maladroitement de faire oublier sa judéité jusqu'à changer de nom, tandis que l'actrice Rachel déclame du La Fontaine avec une sensualité tout orientale. L'œuvre est émaillée 
de propos antisémites, et il est difficile de faire la part chez Proust de la défiance et de l'allégeance au discours antisémite. Le cas d'Irène Némirovsky, examiné par Amotz Giladi, semble tout à fait particulier, car elle véhicule dans son œuvre les principaux thèmes antisémites (association Juif-capitalisme, Juif mentalement et physiquement déformé, portant préjudice aux travailleurs du même domaine) sans renier sa judéité. Sa légitimité gagnée par cette attitude paradoxale, elle la perdra dès 1940, et définitivement en 1942, à Auschwitz.

Pour certains écrivains, c'est une haine de soi que véhicule leur œuvre. Ainsi, selon Louis-Albert Revah, Emmanuel Berl hérite de sa famille maternelle une certaine honte d'être juif et fera sien le discours antisémite suivant lequel les Juifs ne peuvent être tout à fait français, allant jusqu'à collaborer avec Pétain et exprimer dans son œuvre la crainte qu'avec "l'immigration de déchet", culture et civilisation ne se perdent. Notons cependant qu'après 1967, il devient un ardent sioniste.

5 Prenant conscience de son identité juive avec la répression antisémite du régime de Vichy, Bernard Franck, dont Nelly Wolf présente le cas, reprend les thèmes antisémites (Juif déicide, dominateur, violeur) dans la plupart de ses œuvres sous des procédés littéraires lui permettant une double attitude: la bouffonnerie, le retournement de situation (il applique aux antisémites les stéréotypes négatifs qu'ils véhiculent), et la mythomanie. Puis c'est un roman très particulier de Romain Gary qui est analysé par Yves Baudelle : La Danse de Gengis Cohn (1966), livre tout d'ironie qui gagnera les foudres d'Adorno. Un rescapé des camps devient le dibbouk de son tortionnaire nazi et, paradoxalement, c'est l'intrus qui se laisse contaminer par les idées de son hôte. Par l'humour, qui pour Gary est « une défense contre le malheur », il entend dénoncer deux impostures: celle de la culture occidentale impuissante à empêcher l'holocauste et celle de la dénazification de l'Allemagne.

6 Un autre roman, Jacob le menteur (1969), de Jurek Becker, s'approprie l'idée que les Juifs sont des menteurs : ainsi, un Juif fait croire à ses amis du ghetto que les troupes russes arrivent, ce qui leur permet de reprendre espoir et ainsi de résister à la dureté de la vie dans le ghetto. Le héros est ainsi un «imposteur altruiste » qui ment pour sauver les autres et leur rendre la maîtrise de leur destin (même si tout se termine par la déportation).

7 Un rapprochement intéressant est opéré par Nurit Levy entre Doubrovsky et Céline dont l'ambiguiité du discours antisémite est repérée. Doubrovsky reprend les comparaisons animales pour décrire les Juifs et se les attribue à lui-même. Comme Céline, il est à la recherche d'une écriture "pseudo-orale ", celle même dont Céline a dit qu'elle n'était pas accessible aux Juifs, incapables d'émotion spontanée. Dans une forme de masochisme, Doubrovsky se culpabilise d'avoir survécu et reprend à son compte les insultes proférées par Céline à l'encontre des " aryens baisés par les Juifs ». C'est un autre genre d'obsession, entre oubli et mémoire, qui tenaille la génération d'après, comme celle de Marc Weitzmann, journaliste connu dont l'œuvre littéraire n'échappe pas à l'ambiguïté selon Elena Quaglia. Il est tiraillé entre l'inquiétude identitaire et la critique féroce des faux semblants philosémites et veut revendiquer une identité consciente de ses contradictions, en mettant en scène toutes les problématiques liées à la judéité contemporaine.

8 C'est l'obsession sexuelle manifeste du Juif chez Philip Roth qu'étudie Steven Sampson. Dans ses différents romans, il dégage les thèmes récurrents de la désacralisation de la 
religion, du sexe et des renversements tortionnaire-persécuteur et de la violence en prenant comme point de départ le film de Polanski, «Rosemary's baby ».

9 Michèle Tauber se penche, elle, sur le gros roman de David Grossman, Voir ci-dessous, amour, dans lequel la Shoah est une occasion de réfléchir sur l'homme en général en présentant les répercussions de la Shoah sur la vie d'un sabra. À la manière d'un conte à la Shéhérazade, les limites temporelles et spatiales disparaissent, mêlant auto-ironie, thème du dibbouk et désacralisation. C'est aussi à un renversement saisissant que nous invite Bruno Chaouat avec Le transport de A.H. (1981), de Georges Steiner, roman didactique sur l'hitlérisme et l'« antisémitisme rédempteur ». L'auteur met en scène l'argumentaire d'Adolf Hitler, transporté en Amazonie, se présentant comme l'instrument de la logique juive elle-même et se montrant comme le véritable messie. Et Steiner fait le parallèle entre l'élimination des Juifs par les nazis et celle de la forêt amazonienne par l'Occident.

Le dernier article, de Vincent Lowy, est consacré au cinéaste Jean Renoir tel qu'il est présenté dans le film « Voyage à travers le cinéma français » de Bertrand Tavernier. Et de se demander comment ce cinéaste populaire, qui avant la guerre condamnait l'antisémitisme, avait pu se compromettre avec le régime de Vichy et regretter dans une lettre qu'il y ait trop de producteurs israélites, comme pour confirmer la parole de Gabin : « Renoir comme metteur en scène, un génie. Comme homme, une pute ». 